\title{
Injection and Combustion of RME with Water Emulsions in a Diesel Engine
}

\author{
J. Cisek
}

\begin{abstract}
This paper presents ways of using the fully-digitised triggerable AVL VideoScope 513D video system for analysing the injection and combustion inside a diesel engine cylinder fuelled by RME with water emulsions.

The research objects were: standard diesel fuel, rapeseed methyl ester (RME) and RME - water emulsions. With the aid of a helical flow reactor, stable emulsions with the water fraction up to $30 \%$ weight were obtained, using an additive to prevent the water from separating out of the emulsion.

An investigation was made of the effect of the emulsions on exhaust gas emissions $\left(\mathrm{NO}_{\mathrm{X}}\right.$, $\mathrm{CO}$ and $\left.\mathrm{HC}\right)$, particulate matter emissions, smoke and the fuel consumption of a one-cylinder HD diesel engine with direct injection. Additionally, the maximum cylinder pressure rise was calculated from the indicator diagram. The test engine was operated at a constant speed of $1600 \mathrm{rpm}$ and 4 bar BMEP load conditions.

The fuel injection and combustion processes were observed and analysed using endoscopes and a digital camera. The temperature distribution in the combustion chamber was analysed quantitatively using the two-colour method. The injection and combustion phenomena were described and compared.

A way to reduce $\mathrm{NO}_{\mathrm{x}}$ formation in the combustion chamber of diesel engines by adding water in the combustion zone was presented. Evaporating water efficiently lowers the peak flame temperature and the temperature in the post-flame zone. For diesel engines, there is an exponential relationship between $\mathrm{NO}_{\mathrm{x}}$ emissions and peak combustion temperatures. The energy needed to vaporize the water results in lower peak temperatures of the combusted gases, with a consequent reduction in nitrogen oxide formation.
\end{abstract}

The experimental results show up to $50 \% \mathrm{NO}_{\mathrm{X}}$ emission reduction with the use of $30 \%$ water in an $\mathrm{RME}$ emulsion, with unchanged engine performance.

Keywords: diesel engine, RME - water emulsions, injection, combustion, visualization.

\section{Introduction}

Among power-driving combustion engines, diesel engines are the most efficient, and their fuel consumption is $30 \%$ lower than in petrol engines. However, one of the major problems with diesel engines concerns their exhaust gas emissions, which contain excessive amounts of toxic substances, such as nitrogen oxides $\mathrm{NO}_{\mathrm{X}}$ and particulate matter PM. In the light of environmental legislation, attempts to reduce these toxic emissions remain a current issue.

Given the current state of the engineering knowledge, simultaneous reduction of emission levels of the two toxic substances through design modifications to diesel engines is not possible. Recently new gas treatment methods have been developed, though the gas can be treated outside the engine only, after leaving the cylinder. A major disadvantage of these methods is their high costs, which preclude their widespread use.

Extensive research is being undertaken to investigate and modify the conditions for injection and combustion of diesel fuels to eliminate, or at least to vastly reduce, the zones of $\mathrm{NO}_{\mathrm{X}}$ formation (high temperature and rich in oxygen zones) and the zones where conditions are ripe for soot formation.
Theoretical and experimental data available so far has revealed that $\mathrm{NO}_{\mathrm{X}}$ emissions can be most effectively reduced when a carefully prepared fuel-water emulsion is injected into the cylinder. The PM emissions are reduced and, in certain conditions, fuel consumption can also be lowered [8]. However, one issue remains unsolved: how to prepare such an emulsion?

\section{Preparation of the RME-water emulsion}

The experimental program uses a helical flow reactor incorporated in the supply system of the engine. The helical flow of fluids in a ring-shaped slit between coaxial cylinders, the inner one rotating, is interpreted as a combination of Poiseuille's axial flow and Couette's rotating flow. Because of the stability loss, the flowing fluids begin to develop Taylor vortices, which cause intensive mixing. The dispersion factors in the plane perpendicular to the axis tend to be high, whilst the axial dispersion is insignificant (as the flow is induced by piston motion). So far, research data on the dispersion of the two mutually insolvent liquids has revealed that the flow reactor can be used to produce an emulsion in a wide range of fluid flow rates and their actual proportions. 


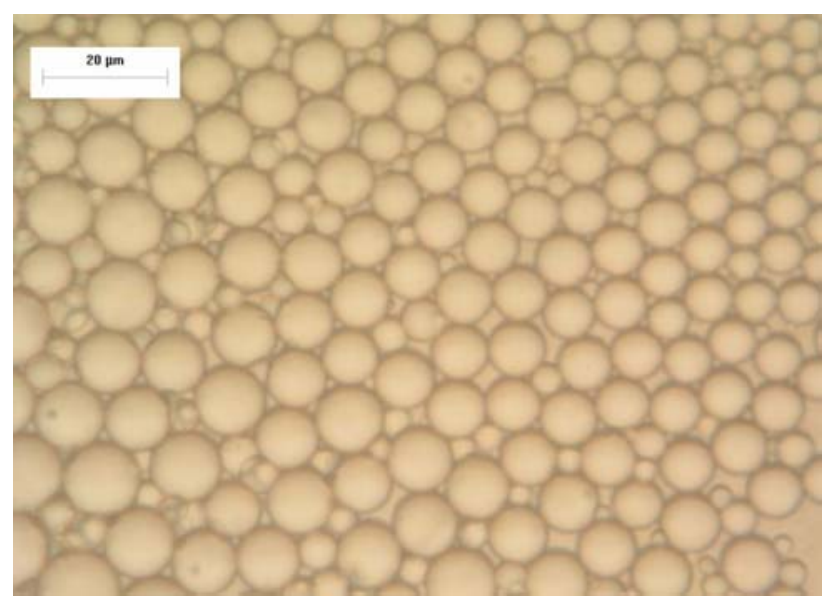

Fig. 1: RME - water emulsion $(30 \%$ of water $-\mathrm{m} / \mathrm{m})$

The helical flow reactor was used to produce stable emulsions of rapeseed methyl ester (RME) and distilled water, the proportion of water being $10 \%$ or $30 \%$ by weight. A surface agent, Rokafenol, was first added to distilled water, in volumetric proportion of $2 \%$, to ensure stability of the emulsion. The emulsion was prepared directly before fuelling the engine.

\section{$3 \quad$ Experimental setup and methodology}

The experimental setup incorporates a one-cylinder HD diesel engine with a direct injection system SB3.1 (cylinder diameter $D=127 \mathrm{~mm}$, stroke $S=146 \mathrm{~mm}$ ) equipped with a 4-nozzle injector, with outlet nozzle diameter $0.34 \mathrm{~mm}$. Measurements were taken at constant speed (1600 rpm and 4 BMEP load conditions), regardless of the fuel type. The engine was fuelled with: diesel fuel (sulphur content $<50 \mathrm{ppm}$ ), rapeseed methyl ester RME, RME-water emulsions (in proportions: $10 \%$ water - $90 \% \mathrm{RME}$ and $30 \%$ water and $70 \%$ of RME, by weight).

The setup for the braking tests (see Fig. 2) incorporates the measurement and control apparatus for measurements of the fast-changing pressures within the cylinder and in the injection installation (AVL Indimeter), a set of analysers to measure the concentrations of $\mathrm{CO}, \mathrm{THC}, \mathrm{NO}_{\mathrm{X}}$, (AVL CEB II), an installation to handle the PM emissions and the AVL VideoScope $513 \mathrm{D}$ video system for visualising the fuel injection and combustion processes. The system enables archiving of injection and combustion images, registered with frequency approaching $0.1^{\circ}$ of the crankshaft rotation angle [1]. The measurement was repeated 10 times for each shaft rotation angle, for the purposes of statistical treatment of the images (to define the probability of the occurrence of an injection and/or a flame). In addition, the two-colour method was applied [1] to determine the isotherm distribution in the diffusion flame in the function of the shaft rotation angle. Subsequent stages of fuel injection, ignition and combustion were monitored for each fuel type.

The effects of the fuel type on the energy-based parameters, toxicity, presence of smoke in the exhaust gas and the maximum rate of pressure rise in the cylinder are addressed below. Of major interest are other parameters of the indicator diagrams, the heat release rates and the injection characteristics.

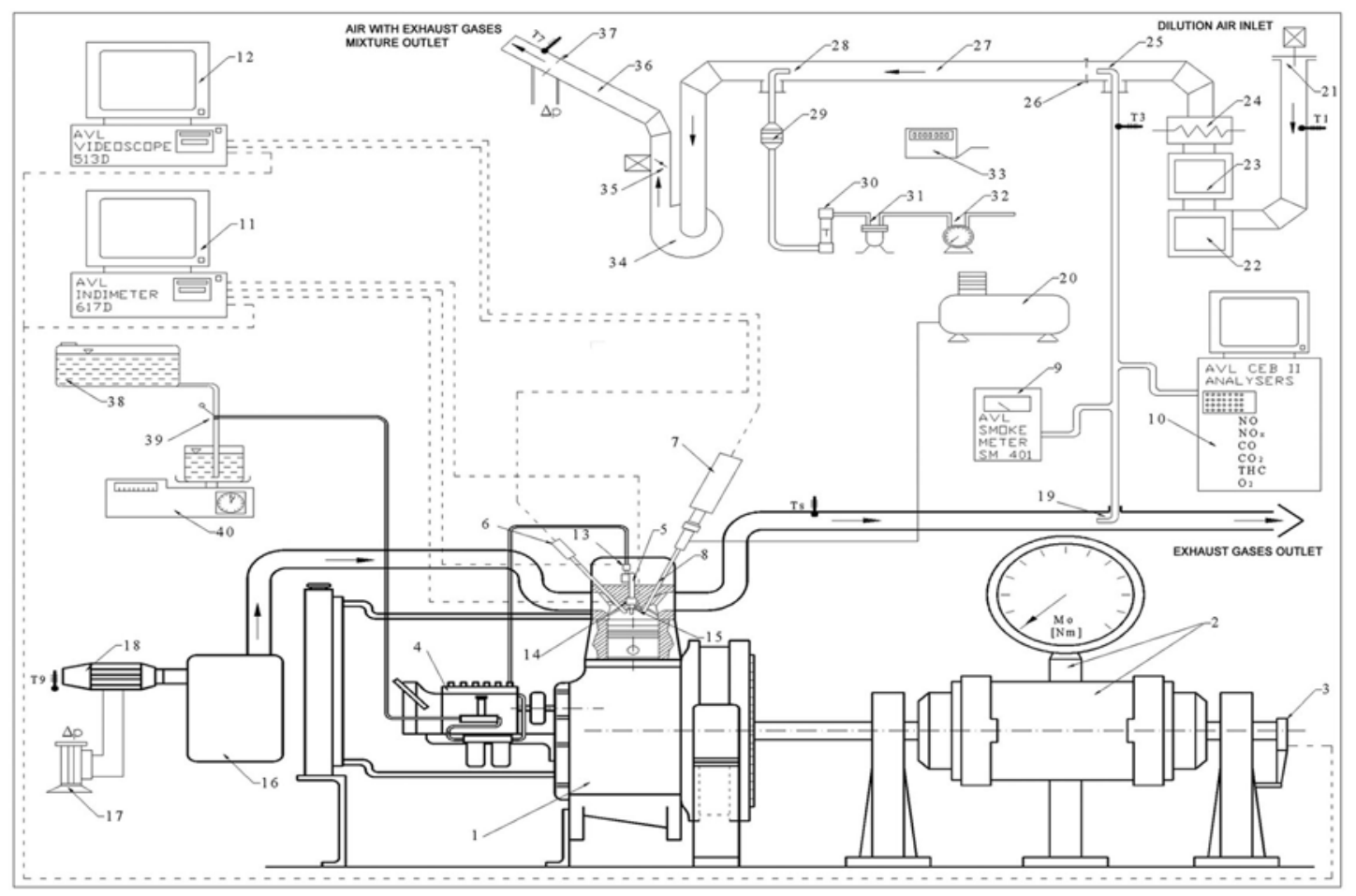

Fig. 2: Experimental setup 


\section{Energy-based parameters of the diesel engine}

During all the tests, the engine was operated at a constant rate of $1600 \mathrm{rpm}$, torque $60 \mathrm{Nm}$ (equivalent to 4 bar BMEP load conditions and effective power $N c=10 \mathrm{~kW}$ ). Of major interest was the temperature of the exhaust gas at the outlet channel. The indicator diagrams yield the retardation of ignition, the maximum rate of combustion pressure rise, and the maximum pressure in the cylinder. Fuel consumption was measured by weight.

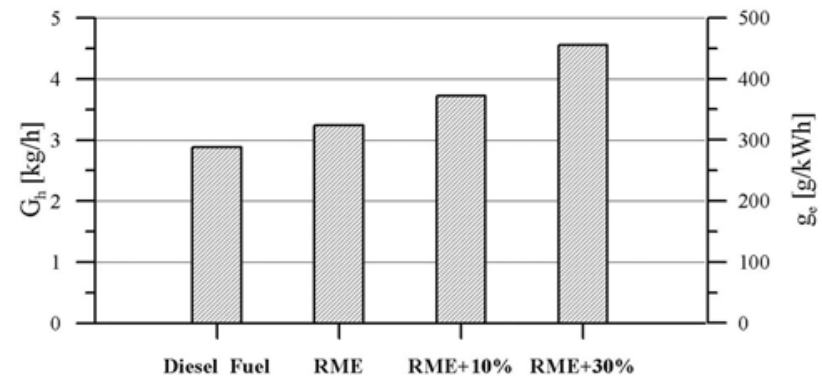

Diesel_Fuel - standard diesel fuel,

RME - rapeseed methyl ester,

$\mathrm{RME}+10 \%$ - emulsion $90 \% \mathrm{RME}+10 \%$ water,

$\mathrm{RME}+30 \%$ - emulsion $70 \% \mathrm{RME}+30 \%$ water

Fig. 3: Fuel consumption $G_{h}$ and specific fuel consumption $g_{e}$ at $1600 \mathrm{rpm}$ and $\mathrm{BMEP}=4$ bar with different fuels

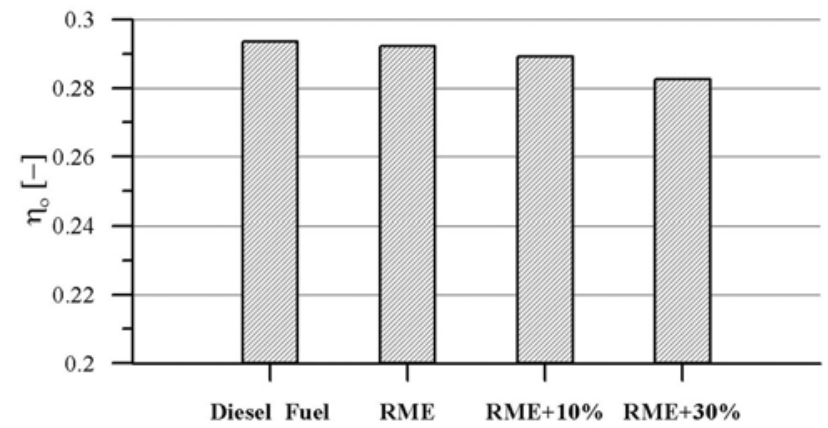

Diesel_Fuel - standard diesel fuel,

$\mathrm{RME}$ - rapeseed methyl ester,

$\mathrm{RME}+10 \%$ - emulsion $90 \% \mathrm{RME}+10 \%$ water,

$\mathrm{RME}+30 \%$ - emulsion $70 \% \mathrm{RME}+30 \%$ water

Fig. 4: Total efficiency at $1600 \mathrm{rpm}$ and $\mathrm{BMEP}=4$ bar with different fuels

The plot in Fig. 3 reveals a major increase in the hourly and specific consumption of rapeseed methyl esters (RME) and its water emulsions. This increase is attributable to the fact that the calorific value of RME $(37.5 \mathrm{MJ} / \mathrm{kg})$ is $1 \%$ lower than that of standard diesel fuel $(42 \mathrm{MJ} / \mathrm{kg})$. In addition, the calorific value of water emulsions of RME is lower by $10 \%$ and $30 \%$ than that of pure RME, since water has no calorific value at all. Still smaller differences between particular fuel types are revealed in the total efficiency plots $\eta_{o}$ as the differences in their calorific value are accounted for.

The total efficiency for RME and diesel fuel is almost identical, approaching $29 \%$, whereas the use of an emulsion with $30 \%$ water content reduces the total efficiency value slightly, to $28 \%$.

The next plot shows the temperature of the exhaust gas measured at the outlet channel. It is apparent that the use of a water emulsion causes a significant reduction in the exhaust gas temperature, which is a most favorable feature particularly at higher loads, when the thermal loading of the engine and turbocompressors becomes critical.

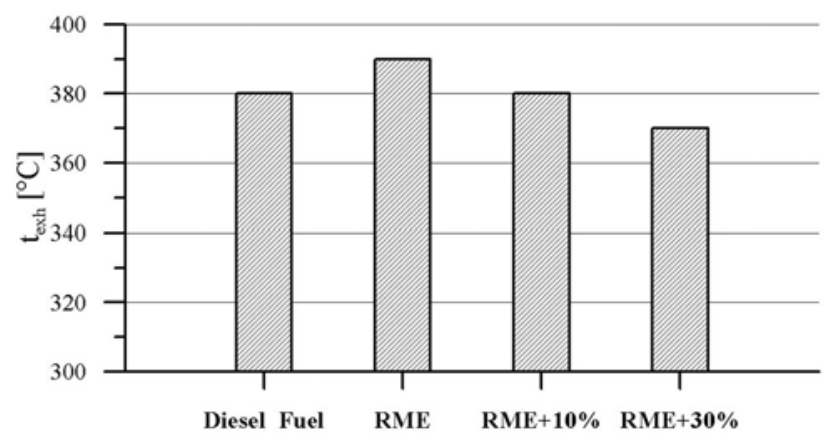

Diesel_Fuel - standard diesel fuel,

RME - rapeseed methyl ester,

$\mathrm{RME}+10 \%$ - emulsion $90 \% \mathrm{RME}+10 \%$ water,

$\mathrm{RME}+30 \%$ - emulsion $70 \% \mathrm{RME}+30 \%$ water

Fig. 5: Exhaust gases temperature at $1600 \mathrm{rpm}$ and $\mathrm{BMEP}=4$ bar with different fuels

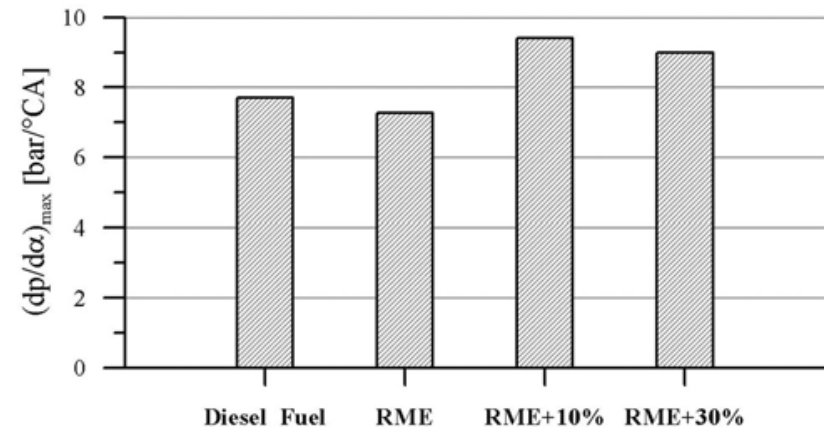

Diesel_Fuel - standard diesel fuel,

$\mathrm{RME}$ - rapeseed methyl ester,

$\mathrm{RME}+10 \%$ - emulsion $90 \% \mathrm{RME}+10 \%$ water,

$\mathrm{RME}+30 \%$ - emulsion $70 \% \mathrm{RME}+30 \%$ water

Fig. 6: Maximum rise of cylinder pressure at $1600 \mathrm{rpm}$ and $\mathrm{BMEP}=4$ bar with different fuels

Depending on the fuel type, the retardation of ignition also varies $\left(10^{\circ}\right.$ of the shaft rotation angle for standard diesel fuel and $9^{\circ}$ for RMR). When the en- 
gine is fuelled with $10 \%$ - and $30 \%$-water emulsions of $\mathrm{RME}$, the retardation of ignition reaches a level of $11^{\circ}$ and $14^{\circ}$ of the shaft rotation angle, respectively. These reports are corroborated by images of the combustion chamber taken at the instant when the selfignition process begins (see Fig. 14 and Fig. 15). Addition of water in the form of an emulsion increases the ignition delay and causes the combustion process to begin more rapidly, as evidenced by the differences in the maximum rate of pressure rise inside the cylinder, well apparent in Fig. 6. The reported difference between RME and its $10 \%$ water emulsion seems the most significant, and is accompanied by a slight increase in the maximum pressure of combustion $p_{\text {cmax }}$, rising from 69 bar (standard diesel fuel and RME) to 71 bar (for a $30 \%$ water emulsion of RME).

\section{Toxicity of the exhaust gas}

Measurements of the gaseous substances constituting the exhaust gas were taken with the AVL CEB II set of analysers, using the hot gas path. The oxygen contents were measured with the PMD paramagnetic analyser, whilst an NDIR infrared nondispersive analyser was used to handle the carbon monoxide and carbon dioxide. The $\mathrm{NO}_{\mathrm{X}}$ emissions were measured by a CLD chemo-luminescent analyser equipped with an $\mathrm{NO}_{2} / \mathrm{NO}$ converter and hydrocarbons $\mathrm{HC}-$ with a ionisation analyser with an HFID hot gas path. The plots below show the proportions of toxic substances in the exhaust gas: nitrogen oxides $\mathrm{NO}_{\mathrm{X}}$, carbon monoxide $\mathrm{CO}$ and incompletely combusted hydrocarbons $\mathrm{HC}$ (re-calculated in terms of propane concentration $\mathrm{C}_{3} \mathrm{H}_{8}$ ).

The PM emissions were obtained by the gravity (gravimetric) method, using a diluting tunnel providing the partial gas flow PFDS and partial sampling. The Bosch smoke number was measured using an AVL SmokeMeter.

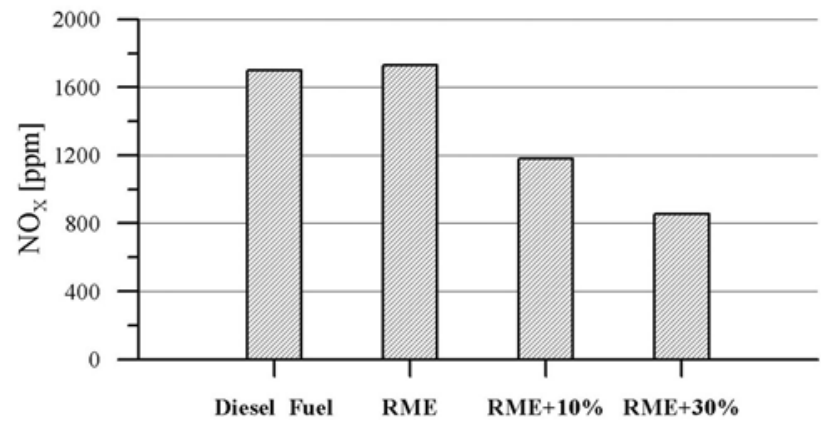

Diesel_Fuel - standard diesel fuel,

RME - rapeseed methyl ester,

$\mathrm{RME}+10 \%$ - emulsion $90 \% \mathrm{RME}+10 \%$ water,

$\mathrm{RME}+30 \%-$ emulsion $70 \% \mathrm{RME}+30 \%$ water

Fig. 7: Nitric Oxides $\mathrm{NO}_{\mathrm{X}}$ concentration at $1600 \mathrm{rpm}$ and $\mathrm{BMEP}=4$ bar with different fuels
This plot shows the $\mathrm{NO}_{\mathrm{X}}$ emissions in the exhaust gas. Fuelling the engine with RME instead of standard diesel fuel causes a slight increase in $\mathrm{NO}_{\mathrm{X}}$ emissions, whilst the use of a $10 \%$ water emulsion of RME reduces the $\mathrm{NO}_{\mathrm{X}}$ contents by $30 \%$. When the $30 \%$ emulsion is used, the $\mathrm{NO}_{\mathrm{X}}$ concentrations are doubly reduced, in relation to pure RME and standard diesel fuel. It is worth mentioning that this is so even though the beginnings of the combustion process are more rapid (Fig. 7).

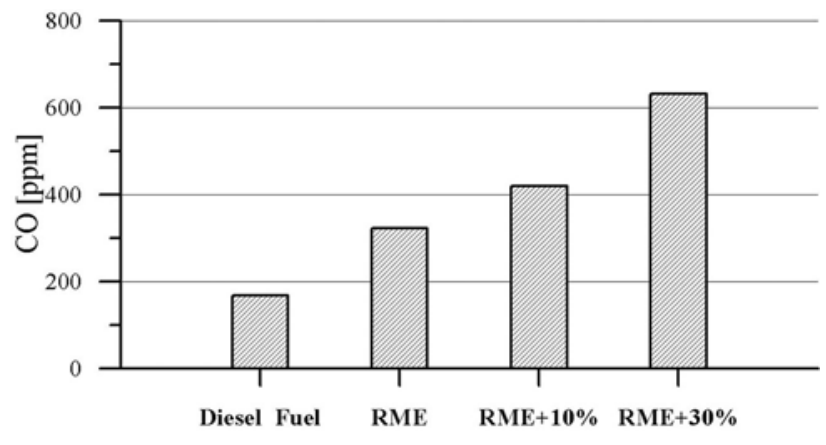

Diesel_Fuel - standard diesel fuel,

$\mathrm{RME}$ - rapeseed methyl ester,

$\mathrm{RME}+10 \%$ - emulsion $90 \% \mathrm{RME}+10 \%$ water,

$\mathrm{RME}+30 \%$ - emulsion $70 \% \mathrm{RME}+30 \%$ water

Fig. 8: Carbon monoxide concentration at $1600 \mathrm{rpm}$ and $\mathrm{BMEP}=4$ bar with different fuels

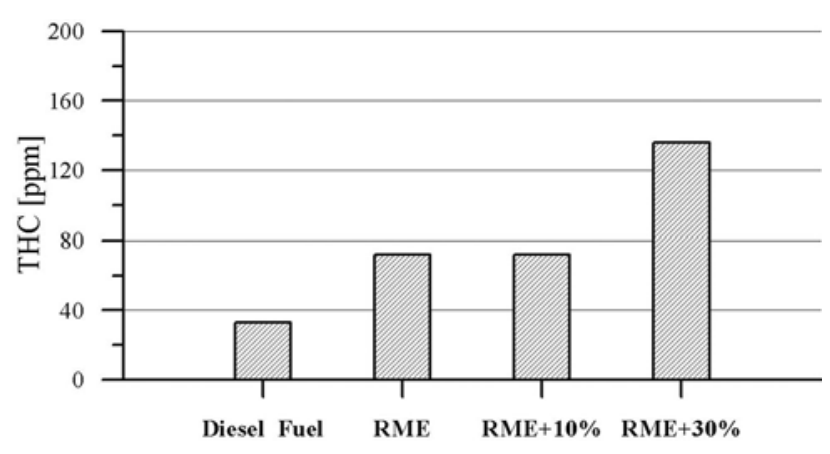

Diesel_Fuel - standard diesel fuel,

RME - rapeseed methyl ester,

$\mathrm{RME}+10 \%$ - emulsion $90 \% \mathrm{RME}+10 \%$ water,

$\mathrm{RME}+30 \%$ - emulsion $70 \% \mathrm{RME}+30 \%$ water

Fig. 9: Total Hydro Carbon concentration at $1600 \mathrm{rpm}$ and $\mathrm{BMEP}=4$ bar with different fuels

$\mathrm{NO}_{\mathrm{X}}$ emissions from engines fuelled by emulsions can be significantly reduced due to the reduction in the local peak combustion temperature, as shown in Fig. 9, mainly due to evaporation of the water contained in the emulsions. This positive effect is attributable to the fact that water droplets injected in the form of an emulsion get directly to the combustion zone. In addition, dilution of gases by water vapour inside the cylinder reduces the local oxygen concentration [8], which causes the thermal formation of $\mathrm{NO}_{\mathrm{X}}$ 
to proceed at a lower rate. In accordance with the Zeldowicz's extended model, the rate of $\mathrm{NO}_{\mathrm{X}}$ thermal formation is associated with the atomic oxygen concentration (coming mainly from dissociation of atmospheric oxygen molecules), and increases exponentially with temperature and the proportion of oxygen.

These two plots show the concentration of carbon monoxide and non-combusted hydrocarbons $\mathrm{HC}$ in exhaust gases. The use of pure RME and its water emulsion causes the $\mathrm{CO}$ and $\mathrm{HC}$ emissions to increase considerably, but this is of little importance as the emission levels are still relatively low and these toxic substances can be largely neutralised by incorporating catalysers in the exhaust system.

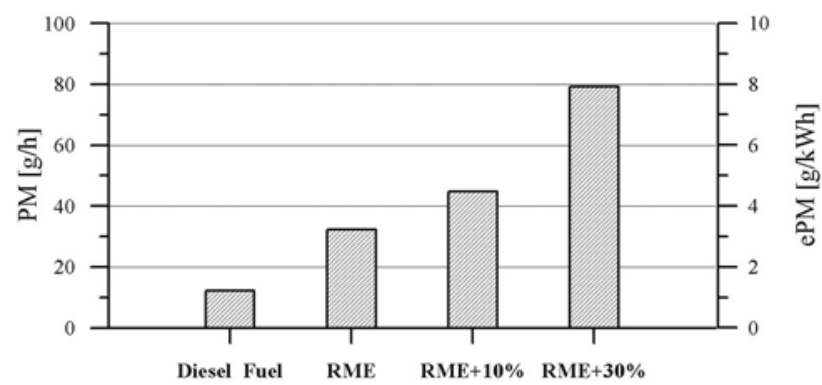

Diesel_Fuel - standard diesel fuel,

RME - rapeseed methyl ester,

$\mathrm{RME}+10 \%$ - emulsion $90 \% \mathrm{RME}+10 \%$ water,

$\mathrm{RME}+30 \%$ - emulsion $70 \% \mathrm{RME}+30 \%$ water

Fig. 10: Emission and specific emission of Particulate Matters at $1600 \mathrm{rpm}$ and $\mathrm{BMEP}=4$ bar with different fuels

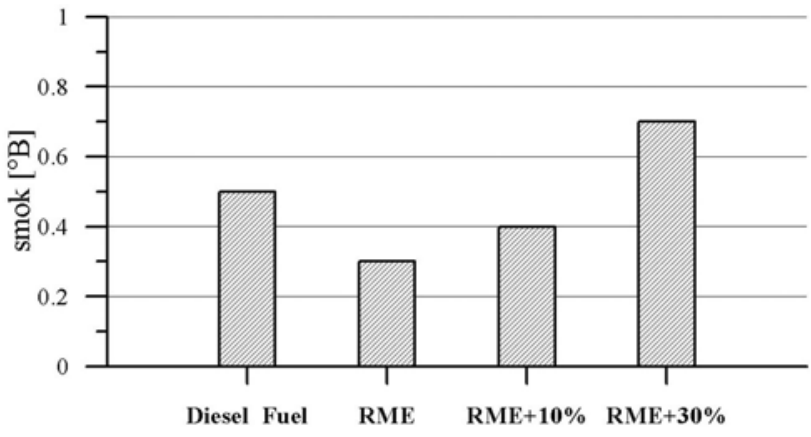

Diesel_Fuel - standard diesel fuel,

RME - rapeseed methyl ester,

$\mathrm{RME}+10 \%$ - emulsion $90 \% \mathrm{RME}+10 \%$ water,

$\mathrm{RME}+30 \%$ - emulsion $70 \% \mathrm{RME}+30 \%$ water

Fig. 11: Bosch Smoke number at $1600 \mathrm{rpm}$ and $\mathrm{BMEP}=4$ bar with different fuels

The plots summarise the Bosch smoke number and the PM hourly and unit emission data. For an engine fuelled by emulsions, the PM emission level and the smoke number increases with increased water content, which may be attributable to the reduced rate of soot afterburning during the combustion process, caused by a significant reduction of the combustion temperature. Measurements of the exhaust temperature seem to corroborate this view. A comparison of the exhaust temperature and the smoke number plots reveals that the higher the temperature of the exhaust gas, the lower the smoke number, which may be attributed to excessive cooling of the combustion zone under relatively small loads.

\section{Visualisation of fuel injection and combustion}

These images are registered with the use of the AVL VideoScope system for visualisation of fuel injection and combustion inside the cylinder. Accordingly, the images were registered from the instant when fuel injection begins right through to the apparent end of the combustion process. The sampling frequency was equal to $1^{\circ}$ of the shaft rotation angle. To enable image recording, the combustion chamber was lit with a stroboscope lamp. The measurement procedure was repeated 10 times for each shaft rotation angle, for the purposes of statistical treatment of the images (to define the probability of the occurrence of an injection and/or a flame). In addition, the two-colour method was applied [1] to determine the isotherm distribution in the diffusion flame in the function of the shaft rotation angle.

Registered images of the fuel injection and combustion process, and measurement data: the rapidlychanging pressure inside the cylinder and the rise of the metering pin for each fuel type were utilised to monitor the subsequent stages of fuel injection, ignition and combustion and to compute the fuel injection rate.

Figs. 12, 13, 14 show the fuel injection and combustion processes registered for the shaft rotation angles corresponding to the selected parameters of the working cycle of the engine. These parameters include: maximum injection rate, commencement of the ignition process (ignition timing) and maximum pressure of combustion.

Figs. 15, 16, 17 show statistically-treated results of 10 repeated measurements taken for each shaft rotation angle, corresponding to the maximum injection rate, the ignition time and the maximum pressure of combustion.

Fig. 18 shows measurement data for the shaft rotation angle corresponding to the maximum pressure of combustion, and also results of image analysis supported by the dedicated thermovision software.

This image was obtained after statistical treatment of 10 data measurements collected for the shaft rotation angle corresponding to the maximum injection rate. In the regions marked in red, a fuel jet was registered during each repeated procedure. This should be interpreted as $100 \%$ likelihood of the occurrence of a fuel jet at that point. In regions marked in black, no 
repeated imaging would reveal a fuel jet. This can be interpreted as $0 \%$ likelihood of the occurrence of a fuel jet. Intermediate colours indicate that a fuel jet was revealed only in some of the repeated measurements.

It is readily apparent that the shape and extent of the fuel jet changes with the increased proportion of water in the emulsion, but that the repeatability of the injection process is impaired.
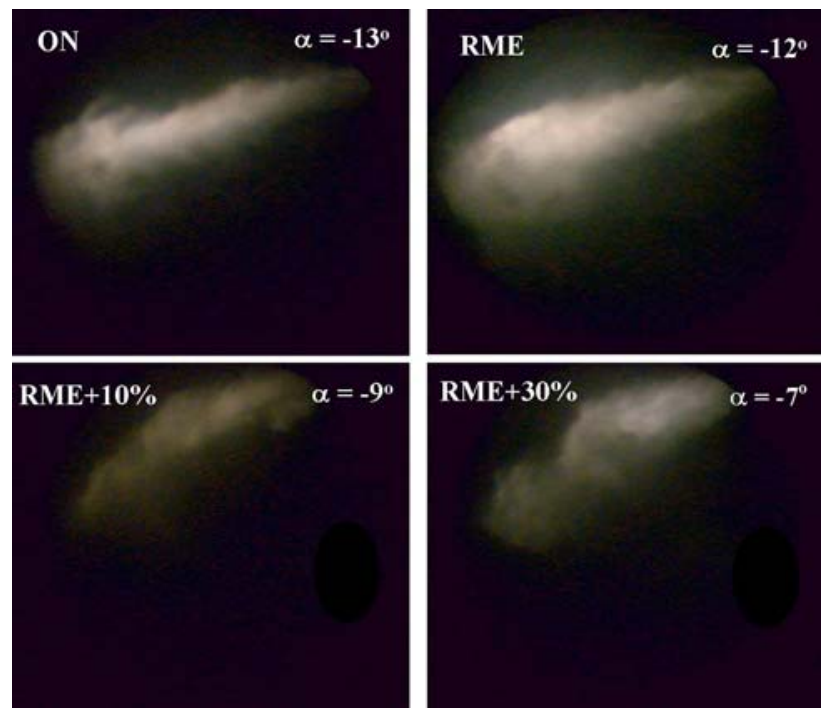

Fig. 12: Image taken inside the combustion chamber (one fuel jet) for the shaft rotation angle corresponding to the maximal injection rate $\alpha_{d q \max }$
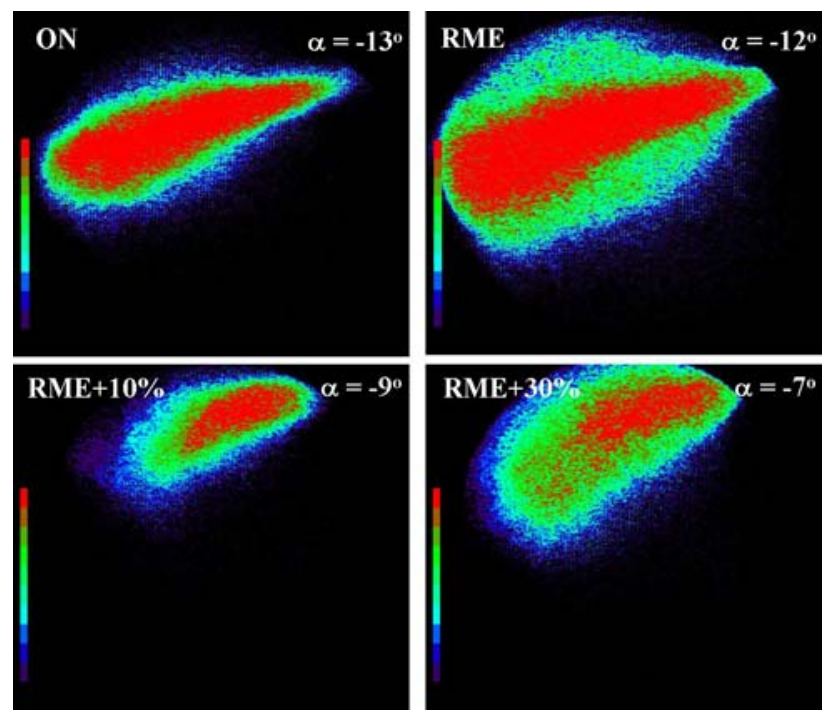

ON - standard diesel fuel,

RME - rapeseed methyl ester,

$\mathrm{RME}+10 \%$ - emulsion $90 \% \mathrm{RME}+10 \%$ water

$\mathrm{RME}+30 \%$ - emulsion $70 \% \mathrm{RME}+30 \%$ water

Fig. 13: Probability of the presence of injected fuel in the given region of the combustion zone for the shaft rotation angle corresponding to the maximum injection rate $\alpha_{d q m a x}$
Fig. 14 shows the images taken inside the combustion chamber at the instant when ignition begins (first visible flames). It appears that the addition of water in the form of an emulsion retards the ignition timing, which is line with the indicator diagrams.
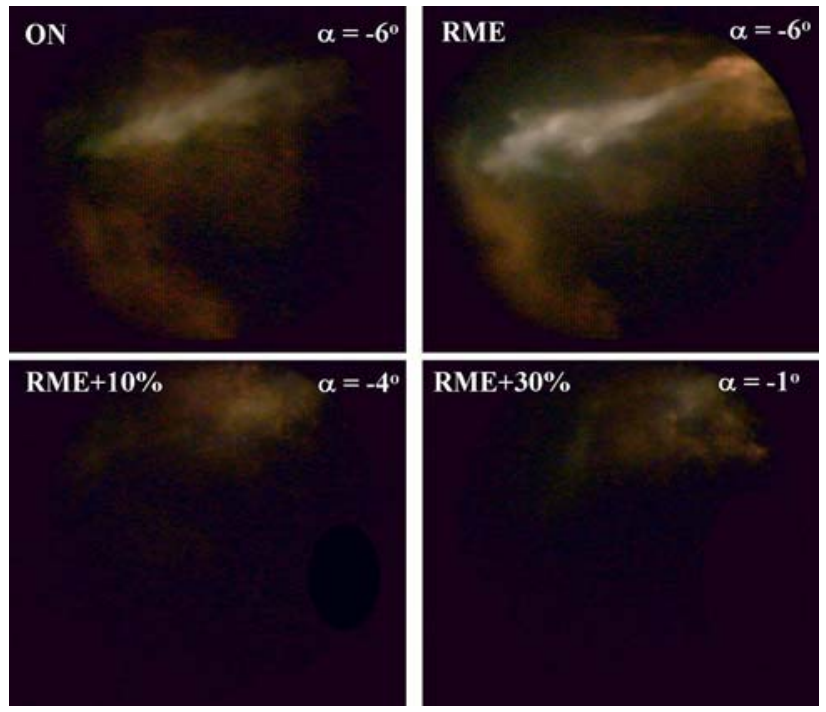

ON - standard diesel fuel,

RME - rapeseed methyl ester,

$\mathrm{RME}+10 \%$ - emulsion $90 \% \mathrm{RME}+10 \%$ water,

$\mathrm{RME}+30 \%$ - emulsion $70 \% \mathrm{RME}+30 \%$ water

Fig. 14: Image taken inside the combustion chamber (one fuel jet) for the shaft rotation angle corresponding to ignition timing $\alpha_{p s}$
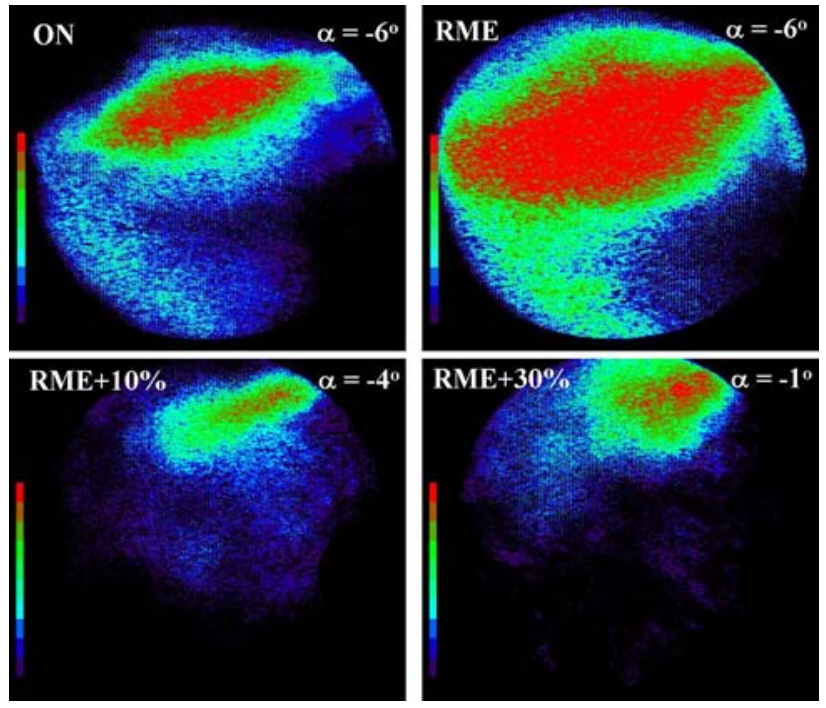

ON - standard diesel fuel,

$\mathrm{RME}$ - rapeseed methyl ester,

$\mathrm{RME}+10 \%$ - emulsion $90 \% \mathrm{RME}+10 \%$ water,

$\mathrm{RME}+30 \%$ - emulsion $70 \% \mathrm{RME}+30 \%$ water

Fig. 15: Probability of the occurrence of a injected fuel or a flame in the given region of the combustion zone for the shaft rotation angle corresponding to ignition timing $\alpha_{p s}$ 
The image in Fig. 15 was obtained after statistical treatment of 10 data measurements collected for the shaft rotation angle corresponding to the ignition timing. In the regions marked in red, a fuel jet or a flame was registered during each repeated procedure. This should be interpreted as $100 \%$ likelihood of the occurrence of a fuel jet at that point. In regions marked in black, no repeated imaging would reveal a fuel jet or a flame. This can be interpreted as $0 \%$ likelihood of the occurrence of a fuel jet or a flame. Intermediate colours indicate that a fuel jet or a flame was revealed only in some of the repeated measurements.

The following drawings show the images and the statistically treated results of image analysis registered for the shaft rotation angle corresponding to the maximum pressure of combustion. This stage of the combustion process is of key importance, featuring the local peak temperatures in the post-flame zones, which in turn determine the amounts of $\mathrm{NO}_{\mathrm{X}}$ being formed [8].
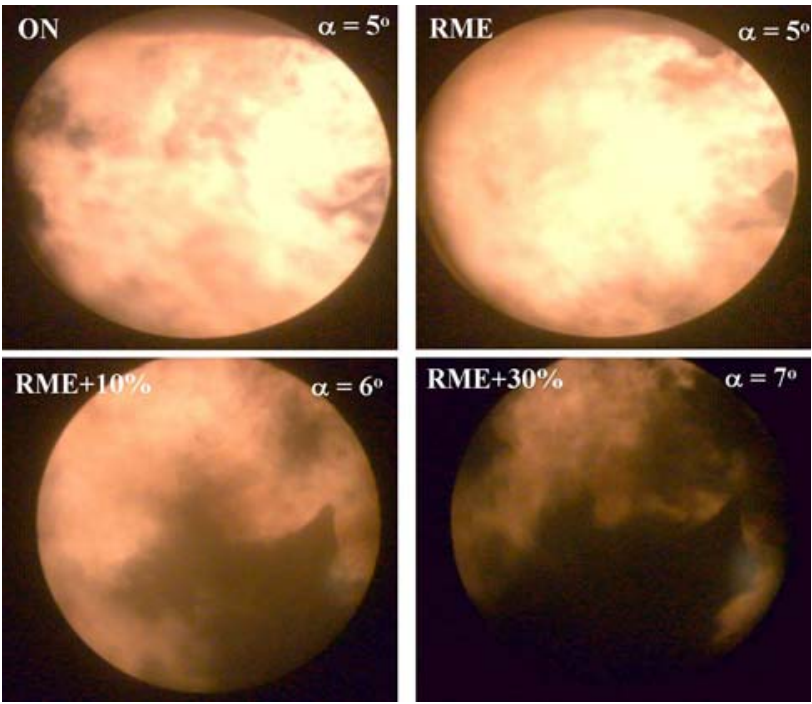

ON - standard diesel fuel,

RME - rapeseed methyl ester,

$\mathrm{RME}+10 \%$ - emulsion $90 \% \mathrm{RME}+10 \%$ water,

$\mathrm{RME}+30 \%$ - emulsion $70 \% \mathrm{RME}+30 \%$ water

Fig. 16: Image taken inside the combustion chamber (one fuel jet) for the shaft rotation angle corresponding to the maximum pressure of combustion $\alpha_{\text {pmax }}$

Fig. 16 shows the combustion process in the same part of the chamber as in the previous images (Figs. 12-14). During this stage of the process a diffusion flame is registered, and a portion of a piston bottom is revealed. The zone of the high-intensity flame is clearly greatest for pure RME, with standard diesel fuel being next in line. For the water emulsions, particularly the $30 \%$ emulsion, the flame is less intense and occupies a smaller portion of the monitored chamber.
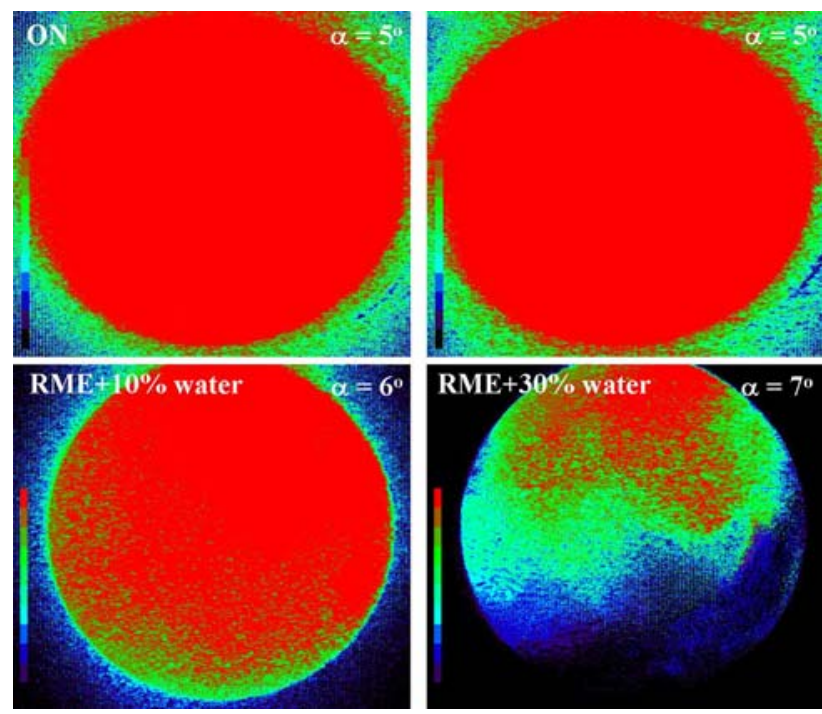

ON - standard diesel fuel,

RME - rapeseed methyl ester,

$\mathrm{RME}+10 \%$ - emulsion $90 \% \mathrm{RME}+10 \%$ water,

$\mathrm{RME}+30 \%$ - emulsion $70 \% \mathrm{RME}+30 \%$ water

Fig. 17: Probability of the occurrence of a flame in the given region of the combustion chamber for the shaft rotation angle corresponding to the maximum pressure of combustion $\alpha_{p \max }$

The shaft rotation angle at which the maximum combustion pressure is registered is similar for all tested fuel types, and the maximum pressures of combustion are also similar.

The two-colour method was applied, supported by dedicated software, to determine the isotherm distribution in the diffusion flame in the function of the shaft rotation angle [1]. The diagrams below show the temperature distribution in the monitored section of the combustion chamber for the shaft rotation angle corresponding to the maximum pressure of combustion. The method is based on an analysis of the diffusion flame radiation spectrum, enabling us to find the temperature distribution inside the combustion chamber, provided that it exceeds $1800 \mathrm{~K}$.

In the case considered here, the temperatures would only slightly exceed $1800 \mathrm{~K}$, because of the relatively low loading (BMEP pressure 4 bar). However, a comparison of the combustion chamber regions occupied by the flame with temperatures in excess of $1800 \mathrm{~K}$ reveals that in engines fuelled with RME the maximum local temperatures are higher than in those fuelled with standard diesel fuel. The use of RMEwater emulsions leads to a significant reduction in the maximum local temperatures: the larger the proportion of water, the more significant the reduction. Accordingly, the $\mathrm{NO}_{\mathrm{X}}$ concentration in the exhaust gases is significantly reduced, as shown in Fig. 5. For $30 \%$ water emulsions, the $\mathrm{NO}_{\mathrm{X}}$ emission level is reduced by nearly $50 \%$ in relation to pure RME or standard diesel fuel. 

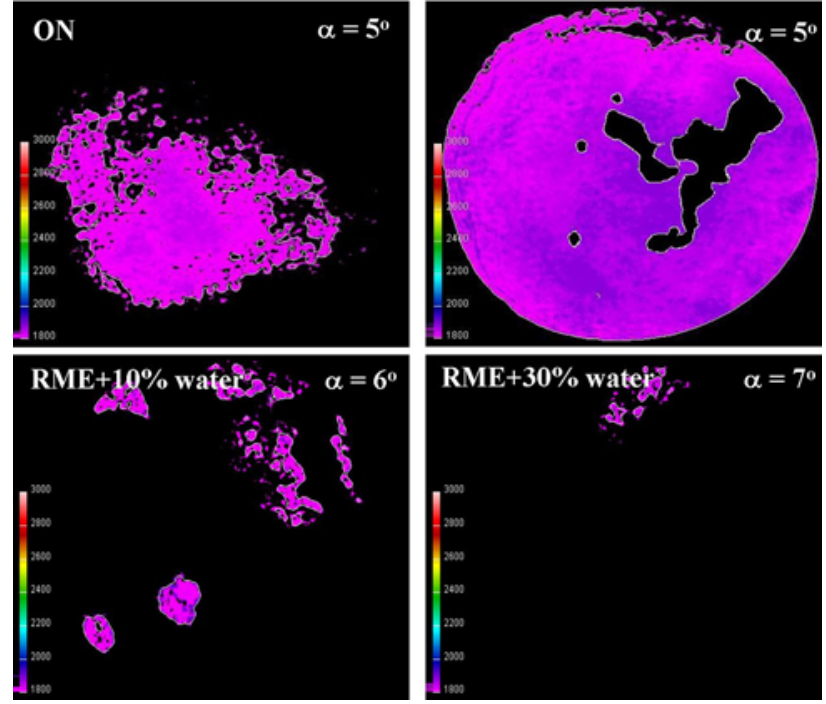

ON - ON - standard diesel fuel,

$\mathrm{RME}$ - rapeseed methyl ester,

$\mathrm{RME}+10 \%$ - emulsion $90 \% \mathrm{RME}+10 \%$ water,

$\mathrm{RME}+30 \%$ - emulsion $70 \% \mathrm{RME}+30 \%$ water

Fig. 18: Temperature distribution in the flame (in excess of $1800 \mathrm{~K}$ ) for the shaft rotation angle corresponding to the maximum pressure of combustion $\alpha_{p \max }$

An analysis of the registered images featuring the injection and combustion phenomena leads us to the following conclusions:

1. Fuel injection proceeds differently, depending on the fuel type. For RME, a cloud of well-sprayed fuel is formed around the injected jet (Fig. 11-12), which is then combusted in a large volume (of the chamber). In the case of RME-water emulsions, the situation is entirely different. No straightforward relationship is available between the proportion of water and the extent and angle of the jet cone for the given emulsion type. Larger proportions of water encourage a greater extent and greater angles of the jet cone and the process is similar to that observed for pure RME. This is attributable to the fact that a low water content in emulsions (from several to around ten percent) would be revealed by the local viscosity extreme. Stable emulsions with $10 \%$ water content displayed the highest viscosity by far, followed by the $30 \%$ water emulsion, RME and standard diesel fuel. For fuels with a low water content, high viscosity leads to a rapid increase in flow resistance as the fuel has to push through the spray nozzle openings. A further increase in the proportion of water reduces the kinematic viscosity of fuels. For emulsions, the injection process is similar to that observed for pure RME.

2. The zone occupied by the flame at the time of ignition is largest for RME and smallest for $30 \%$ water emulsions (Fig. 14-15). This is associated both with the spraying spectrum in the macroscale and with the latent heat required for evaporation of the water contained in the emulsion. Ignition becomes retarded with an increase in the proportion of water in the emulsion.

3. For the maximum combustion pressure (Fig. 16-17), the phenomena inside the cylinder proceed differently for the different fuel types. When the engine is fuelled with RME, the maximum combustion temperatures are higher and, as a result, the $\mathrm{NO}_{\mathrm{X}}$ emissions are higher than when standard diesel fuel is used. Addition of water (to form RME-water emulsions) significantly reduces the "maximum maximorum" temperature of the working medium, both in terms of the duration of the process and the cylinder volume covered by isotherms featuring high combustion temperatures. In consequence, the $\mathrm{NO}_{\mathrm{X}}$ emissions in the exhaust gas are significantly reduced.

\section{Conclusions}

The application of fuel-water emulsions to the fuelling of diesel engines reduces the amounts of toxic substances present in the exhaust gas. The selection of key parameters of the emulsion requires extensive analyses, and the present study is a contribution to the body of research. Research work is now underway in several research centres worldwide $[2,3,4,5,6]$ and also in Poland [10]. Giving a better insight into the processes, and searching for vital relationships between the properties of water-fuel emulsions and energy-based, environmental and operational parameters of the diesel engine will enable Poland to offer a more substantial contribution to the undergoing research work.

\section{References}

[1] Cisek, J.: Options for the Analysis of Fuel Injection using Visual Digitized Methods. Journal of Middle European Construction and Design of Cars, No. 3, September 2004.

[2] Miyamoto, N., Ogawa, H., Wang, J.: Significant $\mathrm{NO}_{\mathrm{X}}$ Reductions with Direct Water Injection into the Sub-Chamber of an IDI Diesel Engine. SAE Transactions, 1995, No. 950609.

[3] Miyano, H., Sungawa, T., Tayama, K., Nagae, Y., Yasueda, S.: The Ship Test For Low-NOX By Stratified Fuel-Water Injection System. $21^{s t}$ International Congress on Combustion Engines. Interlaken 1995. CIMAC 1995.

[4] Murayama, T., Morishima, Y., Tsukahara, M., Miyamoto, N.: Experimental Reduction of $\mathrm{NO}_{\mathrm{X}}$, Smoke, and BSFC in a Diesel Engine Using Uniquely Produced Water (0-80 \%) to Fuel Emulsion. SAE Transactions, 1978, No. 780224. 
[5] Velji, A., Remmels, W., Schmidt, R. M.: Water to reduce $\mathrm{NO}_{\mathrm{X}}-$ Emission in Diesel Engines. A Basic Study. 21 ${ }^{\text {st }}$ International Congress on Combustion Engines. Interlaken 1995. CIMAC 1995.

[6] Mello, J. P., Mellor, A. M.: NOX Emission from Direct Injection Diesel Engines with Water/Steam Dilution. SAE Transactions, 1999.

[7] Merkisz, J., Piaseczny, L.: Wpływ zasilania emulsja paliwowo-wodną na toksyczność i wskaźniki pracy okrętowego średnioobrotowego silnika spalinowego. Journal of KONES 2001, No. 3-4, p. 294-303.

[8] Banot, K.: Wykorzystanie wody w strefie spalania oleju napędowego dla obniżenia emisji $\mathrm{NO}_{\mathrm{X}} \mathrm{w}$ silniku wysokoprężnym. KONMOT-AUTOPRO-
GRES, Czasopismo Techniczne, Wydawnictwo Politechniki Krakowskiej, 6-M/2004, p. 79-86, 2004 .

[9] Cisek, J.: Research Project No. 5 T12D 03325. Politechnika Krakowska. Kraków, 2008.

[10] Szlachta, Z., Cisek, J.: Research Project No. 8 T12D 035 20. Politechnika Krakowska. Kraków, 2008.

Jerzy Cisek, Ph.D., M.E.

Phone: +048 (12) 6283675

E-mail: jcisek@pk.edu.pl

Cracow University of Technology

Institute of Automobiles and Internal

Combustion Engines, Division of Diesel Engines 31-864 Kraków, al. Jana Pawla II 37, Poland 